\title{
Seismic processing, inversion, and AVO for gold exploration - Case study from Western Australia
}

\author{
Christopher B. Harrison ${ }^{1}$ and Milovan Urosevic ${ }^{2}$
}

\begin{abstract}
We investigate the potential of using high-resolution seismic methods for rock characterization and for targeting of gold deposits at the St. Ives gold camp. The application of seismic methods in hard-rock environments is challenged by complex structures, intrinsically low signal-to-noise ratio, regolith distortions, and access restrictions. If these issues can be addressed, then the unparalleled resolving power of reflection seismic can be used for mineral exploration. Appropriate spatial sampling of the wavefield combined with a survey geometry design and rigorous data processing to incorporate high fold and long offsets are necessary for creation of high-quality seismic images. In the hard-rock environment of Western Australia, accurate static corrections and multiphase velocity analysis are essential processing steps. This is followed by a rigorous quality control following each processing step. In such a case, we show that the
\end{abstract}

role of reflection seismic could be lifted from mere identification of first-order structures to refined lithological analyses. Five deep boreholes with sonic logs and core sample test data were used to calibrate 2D seismic images. Despite seismic images were produced with relatively robust scaling it was possible to achieve reasonably high seismic-log correlation across three of the tightly spaced boreholes using a single composite wavelet. Amplitude-versus-offset (AVO) analysis indicated that goldbearing structures may be related to elevated AVO effect and increased reflectivity. Consequently, partial stack analysis and acoustic and elastic inversions were conducted. These results and impedance crossplots were then evaluated against known gold occurrences. While still in the preliminary stages, hardrock seismic imaging, inversion, and the application of AVO techniques indicated significant potential for targeting mineral reserves.

\section{INTRODUCTION}

With the world demand for gold almost equivalent to the demand for petroleum, and with gold reserves increasingly more difficult to locate, the introduction of innovative techniques to explore for this precious resource is needed. World gold mining reached its peak in 2001 (Denham, 2008) and most easy-to-find deposits already have been discovered. The challenge now is to exploit deeper geologic structures, extend the life of present mining operations, and also to discover new sources of the resource. Seismic methods ideally are suited for exploration of deep mineral resources because they have vastly superior resolution in comparison to any other geophysical technique. In hard-rock environments, seismic methods are known to produce very high-quality structural images as documented by Juhlin (1990), Milkereit et al. (1996), Perron and Calvert (1998),
Urosevic et al. (2005), and many others. The use of reflection seismic for hard-rock characterization and direct targeting of mineral resources is still in preliminary stages (Urosevic et al., 2007). This paper proposes to undertake an enhancement of our current understanding of these techniques. The feasibility of seismic methods for mineral exploration has been tested in Yilgarn craton of Western Australia over the last two decades (Urosevic et al., 2007). The application of seismic exploration in brown fields of Western Australia still faces many challenges. Excessively complex structures, rock alterations, thick regolith cover, and poor reflectivity in some areas present major challenges for seismic imaging. Similarly, the Archaean mesothermal gold mineralization are main structural targets of very high complexity (Cox and Ruming, 2004). Low-to-high order shear zones, reverse faults, relaxation faults, and altered and fractured zones surrounding granite intrusions are of crucial

Manuscript received by the Editor 13 December 2011; revised manuscript received 28 June 2012; published online 6 September 2012.

${ }^{1}$ Formerly Curtin University of Technology, Perth, Western Australia; presently CREWES, University of Calgary, Canada. E-mail: harrisc@ucalgary.ca.

${ }^{2}$ Curtin University of Technology, Perth, Western Australia. E-mail: m.urosevic@curtin.edu.au.

(C) 2012 Society of Exploration Geophysicists. All rights reserved. 
importance for mineral precipitation because these structures provide pathways to hydrothermal solutions. Significant gold often is found in small-scale discontinuities that require very high seismic resolution to be imaged. Unfortunately, these complex structures are time-delayed and distorted by a significant regolith cover (20$100 \mathrm{~m}$ thick) comprised of reworked, altered, and weathered material, which is highly heterogeneous and attenuative and hence effectively band-limit the received seismic signal. In addition, seismic exploration for gold across an active mine site experiences excessive ambient noise and environmental and access restrictions, which often impose irregular seismic line geometries. Consequently, it is necessary to optimize acquisition parameters to enhance the signal-to-noise ratio $(\mathrm{S} / \mathrm{N})$ by using powerful sources such as heavy vibrators and combining these with highfold and spatially dense receiver arrays. Good $\mathrm{S} / \mathrm{N}$ requires that the reflectivity is beyond a threshold that is at least above the ambient noise level. To establish the reflectivity, we need to measure the elastic properties of the rocks, which in turn enable us to understand seismic response over the area of investigation as required to ascertain rock characterization.

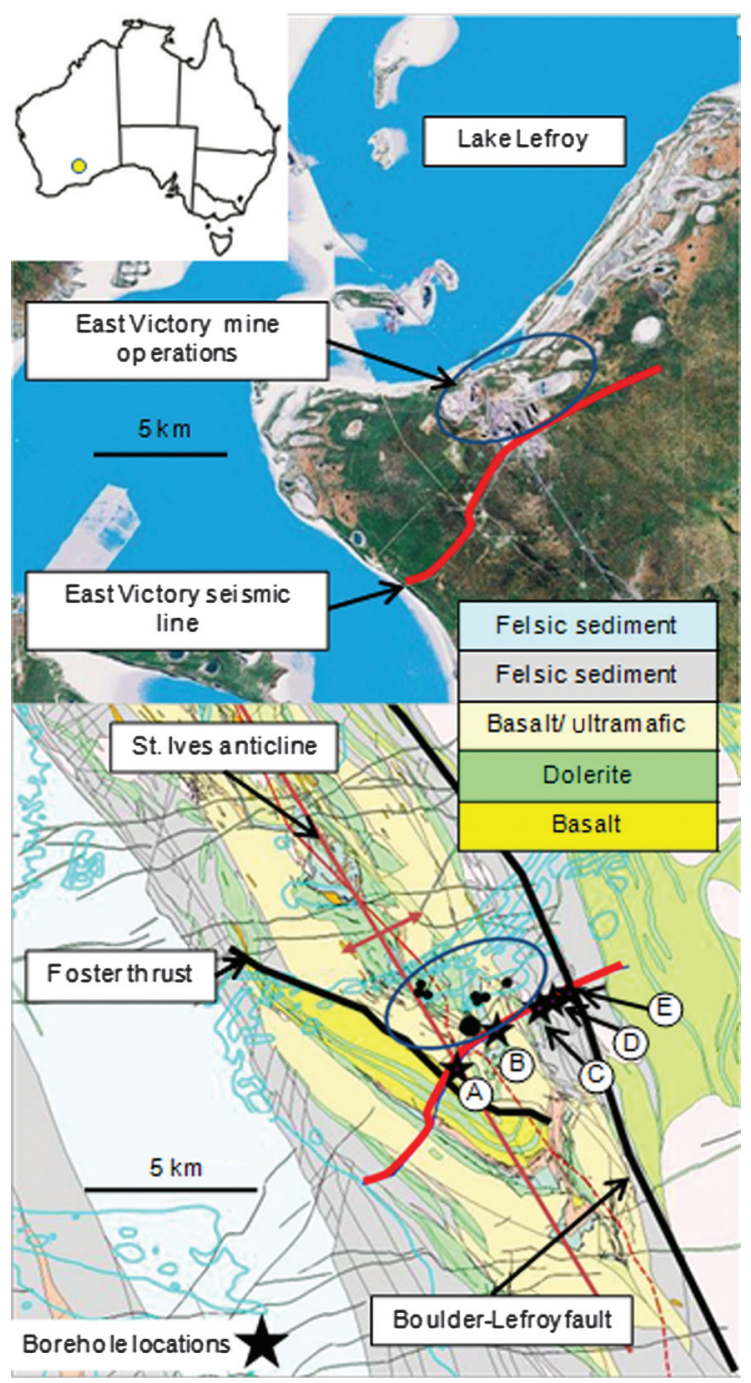

Figure 1. The St. Ives gold camp is located in Western Australia $60 \mathrm{~km}$ south of Kalgoorlie.
Ideally, elastic rock properties are obtained from in-situ measurements using full waveform sonic (FWS) logging tools, which provide information on the compressional $\mathrm{P}$-wave and shear $\mathrm{S}$-wave velocities, plus the density log. Alternatively, velocity and densities can be measured in core sample in the laboratory to create "pseudo logs," which, when combined with vertical seismic profiling (VSP), can be used to calibrate seismic images (Urosevic et al., 2007). The most comprehensive statistical analysis of the rock properties in relation to rock type, structure type, and alteration type is obtained from FWS logs. Density logging is essential for this process but often is avoided in Western Australia due to the risks associated with active sources. Thus, under current practices in Western Australia, density logging often is replaced by core sample measurements. Once the impedance $\log$ is built, the well-tie or seismicto-log calibration is achievable. This calibration is necessary for rock identification and subsequently for seismic impedance inversion and amplitude-versus-offset (AVO) attributes. Seismic inversion, particularly poststack, routinely is used in oil and gas exploration but remains largely untested in hard-rock environments due to: (1) scarcity of borehole logs, (2) lack of 3D seismic data, (3) highly complex geologic structures, (4) nondiscriminative correlation between rock type and acoustic impedance, and (5) poor database documenting the elastic properties of rock alterations (Harrison and Urosevic, 2009). Other issues relate to the line geometry, ambient noise, and recording geometry.

To further progress along the path of hard-rock characterization from seismic data, one of the key tasks is to introduce additional seismic attributes to evaluate the response of complex mineral composites and rock alterations. A more straightforward approach would be to limit these investigations to mineral bearing rocks only. For that purpose, an extensive "seismic response database," compiled from log measurements, core sample tests, and in-situ geologic knowledge is required to advance targeting of mineralized rocks. This is particularly true in the case of gold exploration where additional difficulties include no direct geophysical signature for gold and excessively complex structures and rock alterations.

\section{THE ST. IVES GOLD CAMP}

The St. Ives gold camp is located near Kambalda, $60 \mathrm{~km}$ south of Kalgoorlie in the Eastern Goldfields Province, Western Australia (top Figure 1). The camp itself is $40 \mathrm{~km}$ long and $10 \mathrm{~km}$ wide trending south-southeast from Kambalda on the southern tip of the Norsemen-Wiluna greenstone belt of the Yilgarn craton. The color of Lake Lefroy on Figure 1 slightly is misleading, because the lake is a salt lake and extremely muddy most of the year.

The Yilgarn craton has accounted for almost $80 \%$ of the cumulative gold production of Western Australia up to 2001 (Cassidy and Hegemann, 2001). The Kambalda dome, which is an Archaean mafic sequence on the Yilgarn craton, is of key importance to this research. The dome is comprised of basalts, ultramafics, and interflow sediments, and lies in an important active mining location in Western Australia. The St. Ives gold complex is located within the core of a regional-scale north-northwest-trending Kambalda Anticline that envelopes the Kambalda Dome to the north-northwest. Gold mineralization is disseminated within shear zones or hosted by quartz veins or breccias, localized within low-displacement reverse shear zones up to $1 \mathrm{~km}$ long with maximum displacement of up to a few hundred meters. Many of the mineralized shears are local structures such as the Playa shear zone, which is a large 
structure extending for 10 to $15 \mathrm{~km}$ south of the Kambalda Dome. The dome is considered to be a second-order structure, related to the major regional Boulder-Lefroy shear zone (Vearncombe, 1998; Cox and Ruming, 2004; Weinberg et al., 2005). Gold typically is contained within 2 to $10 \mathrm{~m}$ wide thrust/shears but also is associated with stock-works and vein arrays that have been developed in brittle host rocks such as the Kapai Slates and the felsic-to-intermediate lithologies, in breccia zones and central, quartz-rich, and mylonitic parts of shear zones that are invariably only minor structures.

Intermediate and felsic porphyry dykes are also of interest because gold mineralization has a frequent occurrence near these structures (Drummond et al., 2000). While these complex structures widely are different in scale, all can host gold mineralization. Because gold characteristically are associated with certain lithological formations, structural and lithological understandings are crucial for gold targeting.

\section{SEISMIC DATA ANALYSIS — EAST VICTORY LINE}

During seismic campaigns in 2002 and 2004, fifteen high-resolution 2D seismic lines were acquired over the central and southern parts of Kambalda dome. The East Victory seismic line, which is of particular interest to this study, was acquired over known gold deposits at the St. Ives gold camp. The data were part of a highresolution seismic experimental program conducted for Gold Fields Limited in 2002. This high-resolution survey was conducted after a regional seismic survey had established that large-scale hard-rock reflection-imaging was possible for deeper targets, but did not produce usable images of shallow targets under $1000 \mathrm{~m}$ (Goldby et al., 1997). The experimental Victory high-resolution seismic line was undertaken to assess the feasibility of seismic methods for imaging shallow structures in the range of 100 to $1000 \mathrm{~m}$ depth. The track of the Victory line with respect to the dome and the regional geology is shown on the bottom of Figure 1. The geologic map presents the main geologic features of the area including the St. Ives anticline. The seismic line was designed to image the main structural features including the Boulder-Lefroy Fault, the Foster Thrust, mine-scale features as well as the base of a known mafic package, felsic mineral deposits beneath the Victory mine, listric structures, and flat-lying stratigraphy at the prospect scale, shallower than $500 \mathrm{~m}$ (Stolz et al., 2004). Table 1 shows the acquisition parameters for the East Victory seismic line.

The goal of the processing of the East Victory seismic data was to produce accurate time and depth seismic images while preserving as much as possible the amplitude, phase, and frequency content. In this process, exceptional accuracy of static correction computation is essential to address regolith heterogeneities. Complete details for static corrections can be found in Cox (1999), with methods for hard-rock seismic data shown by Hatherly et al. (1994) and special identification of the method by Urosevic et al. (2005). Careful application of single channel and conservative use of multichannel filtering was required for removal of coherent and random noise while retaining primaries and their original bandwidth. A multipass constant velocity stack (CVS) analysis using the full-line-length was a key for deriving a geologically plausible velocity field. The standard hard-rock processing flow we use for 2D hard-rock seismic data processing in the Kambalda area is shown in Table 2. Additional processing involves full prestack time and depth migrations. True relative amplitude processing is, strictly speaking, not possible with 2D seismic because the wavefield scattering is a $3 \mathrm{D}$ phenomenon and cannot be compensated for by $2 \mathrm{D}$ processes. In addition, high ambient noise and frequent large lateral variation of reflectivity require more robust scaling, which involves application of automatic gain control (AGC). The effect of this, in the general amplitude nonpreserving process, is "softened" by using a very long AGC window for the computation of scaling operator.

Table 1. Acquisition parameters for the East Victory seismic line.
Instrument

Sample rate

Record length

Source type

VP interval

Sweep type

Sweeps

Receiver array

Receiver interval

Spread

Near and far trace

Coverage
ARAM24 NT recording system $1 \mathrm{~ms}$

$4000 \mathrm{~ms}$

$2 \times$ Hemi60

20 and $10 \mathrm{~m}$

Linear, $2 \mathrm{x} 12 \mathrm{~s} / \mathrm{SP}$

12-100 Hz, 20-120 Hz

12 geophones inline

$10 \mathrm{~m}$

240 groups per shot record

5 and $1195 \mathrm{~m}$

60 and 120 fold
Table 2. Standard (basic) hard-rock processing flow.

1. Geometry assignment and binning

2. First-break picks and refraction static computation

3. Quality control in common shot and common receiver domain 4. Preprocessing $\mathrm{S} / \mathrm{N}$ tests (amplitude compensation, filtering, deconvolution)

5. Amplitude compensation (shot rms equalization, spherical divergence)

6. Spiking deconvolution, band-pass filter

7. Surface-wave noise attenuation

8. Spectral whitening

9. Band-pass filter

10. AGC (1000 ms window)

11. CVS along the full line length

12. Brute stack one

13. Computation of surface consistent residual reflection statistics corrections

14. Application of residual statics

15. Second-pass velocity analysis (CVS)

16. Residual statics (second pass) and Brute stack two

17. DMO corrections (shot domain)

18. Inverse NMO and final velocity analysis (interactive semblance)

19. Final DMO stack

20. Poststack migration

21. Depth conversion 
Two steps, static corrections, and dynamic or normal moveout (NMO) corrections, are essential for the formation of coherent images in the Kambalda region. Accurate statics require each shot record to be precisely picked, which is often the most cumbersome step in hard-rock processing. Velocity analysis is not a trivial process in hard-rock environments. The best insight into the lateral velocity variation is achieved by the application of CVS analysis (Urosevic and Juhlin, 2007). As suggested by Urosevic et al. (1997), the CVS analysis can reveal the following:

- $\quad$ Steeply dipping events appearing with low-stacking velocities originate from out-of-plane structures (typically from shallow depths or discontinuities within the regolith).

- Steeply dipping events expressed on very high velocities $(7.5-10 \mathrm{~km} / \mathrm{s})$ may be difficult to fully preserve in the final

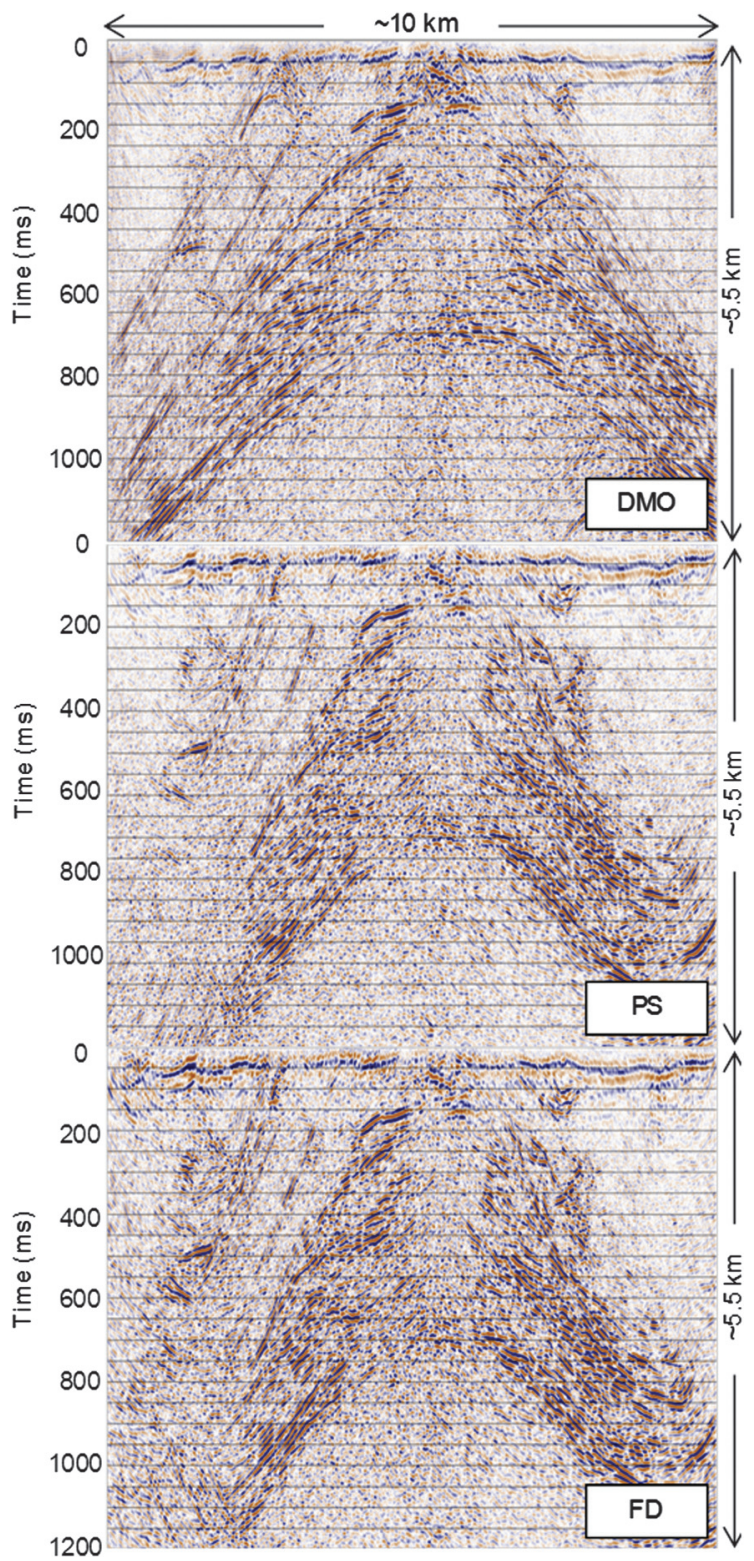

Figure 2. Comparison between the dip moveout (top), phase shift migration (middle), and finite difference migration (bottom) processing results. stack, despite dip moveout (DMO) corrections. Hence, CVS panels should be saved to help facilitate final interpretation.

- Events expressed over very narrow velocity ranges commonly originate from the projections of the deeper structures, which are oriented unfavorably with respect to the line direction.

The existence of out-of-plane energy is further verified by the poor performance of DMO and migration (Urosevic and Juhlin, 1997).

Several iterations of constant velocity staking were conducted to generate the final velocity model. Figure 2 illustrates the results of DMO (top), phase-shift migration (middle), and finite-difference migration (bottom) after several iterations of velocity analysis. Steeply dipping events are emphasized well after DMO application. Further image enhancement is achieved with wave equation migration. Very good performance of DMO and migration suggest that most of the reflection energy originates within the processing plane as proposed by Urosevic and Juhlin (2007).

\section{SEISMIC INTERPRETATION}

Hard-rock seismic interpretation typically is hindered by low S/ $\mathrm{N}$, complex structures, and the lack of deep borehole logs. In the case of the East Victory line, the $\mathrm{S} / \mathrm{N}$ is high and we have five boreholes fully logged along the line (A, B, C, D, and E in Figure 1). The mail geologic features are indicated in Figure 3. The projection of the Condenser dolerite, the projection of the Repulse fault from mine interpretations, and the surface projection of the Foster Thrust onto the seismic image all have been confirmed by Gold Fields geoscientists. The regional greenstone package is interpreted below the anticline by Stolz et al. (2004). Crustal scale shear zones, identified by the variable reflectivity within the greenstone package in Figure 3, are potential contributors to mesothermal gold mineralization in the area. These structures suggest that deep sources of mesothermal fluid have followed the contours of the anticline upward through the green-stone package. Possible alteration plumes through shear zones on the flanks of the anticline, weak zones at rock types in contact associated with gold mineralization (basalt,

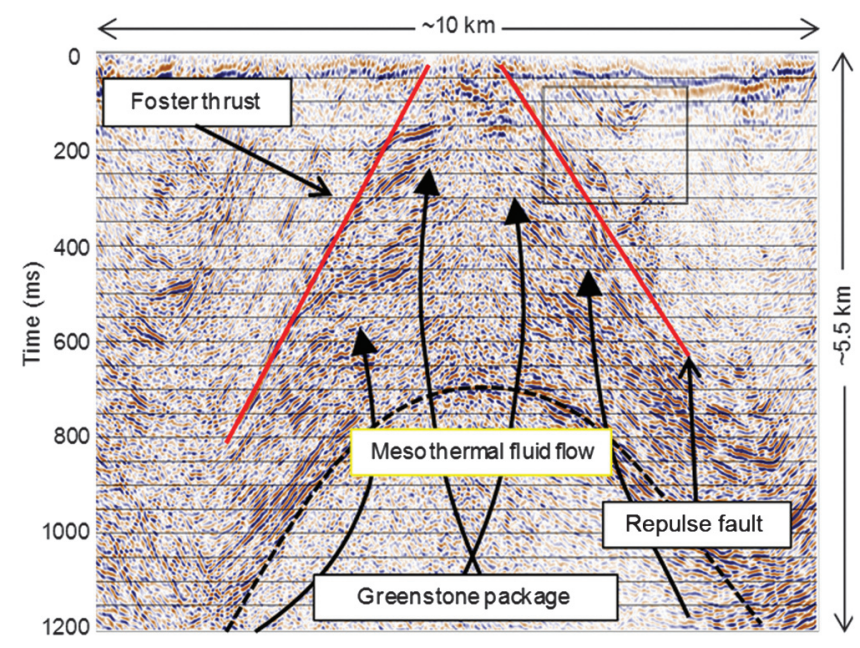

Figure 3. Migrated seismic image of the East Victory line. The box indicates the area of interest where three of the five boreholes are located. 
dolerite, and intrusive), and the lateral and vertical extent of these features are of interest for mining. Relaxation faults near the bottom of the regolith between 200 and $800 \mathrm{~m}$ are also of particular interest for gold mineralization. Finding these "direct" indictors of gold mineralization on the seismic image are extremely encouraging for targeted drilling.

\section{SEISMIC CALIBRATION AND INVERSION}

While focusing of seismic reflectors has been successfully achieved on the East Victory line, the origin and depth of those reflections are ambiguous until calibrated. As indicated on Figure 1, a total of five boreholes were available for comprehensive analysis and calibration. A close-up of three borehole trajectories is shown in Figure 4.

The degree of correlation between the seismic reflections and the log-derived synthetic seismograms critically affects the reliability of seismic inversions. The success of any well-tie depends on many factors such as $\mathrm{S} / \mathrm{N}$ ratio, image accuracy, relative amplitude preservation, log quality, etc. While we did not adhere to true amplitude processing, in our experience, a long-window AGC operator does not affect the amplitudes in a critical way. Moderate to poor-quality $\operatorname{logs}$ and the absence of a VSP, and hence check shots, made the correlation process more challenging than the relative error in amplitudes introduced potentially by AGC. Another difficulty relates to "horizon" picking, which in hard-rock environments has a somewhat different meaning due to a "piecewise" nature of geology. This also affects the wavelet extraction process and its harmonization between the boreholes, across the length of the seismic line.

Wavelet extraction used the cluster of boreholes $(\mathrm{BH} 1, \mathrm{BH} 2$, and BH3) as illustrated in Figure 4. The statistical zero-phase wavelet extracted from the data produced a wavelet with dominant frequency of approximately $50 \mathrm{~Hz}$. This wavelet was used for the initial correlations across the three boreholes. Subsequent wavelet extractions used multiple boreholes (three), resulting in a composite well-based wavelet that maximized overall degree of correlations across five boreholes. An average phase rotation of $67^{\circ}$ is required to zero-phase the seismic data. The correlation results for $\mathrm{BH} 1$, $\mathrm{BH} 2$, and $\mathrm{BH} 3$ were relatively low by oil industry/sedimentary rock standards, but correlation of $65 \%-70 \%$ achieved in this case is quite satisfactory for a $2 \mathrm{D}$ line in a hard-rock environment. We add that deviated borehole trajectories and poor log quality also are factors affecting the correlation process. These factors will further introduce errors into the wavelet estimate. Considering all the factors affecting the well-tie process in hard-rock seismic, the correlation level achieved for Victory line is perceived as very good.

For a model-based impedance inversion, seismic "horizons" have to be interpreted across the line to allow extrapolation of the impedance model away from the logs (Hampson and Galbraith, 1981). As discussed previously, in a hard-rock environment, reflections can be produced also by the alterations in rock type, shear zones, intrusives, and related fractures rather than originating solely from different lithological units in contact. Figure 4 shows interpreted rock-contacts along the East Victory seismic data. The main rock-contacts interpreted on the seismic data are:

- Black Flag-banded iron formation near the Condenser dolerite,

- a high gold content contact between an intermediate intrusion through the Condenser dolerite,
- dolerite/intermediate intrusion into a shear zone, a low-amplitude reflection zone, the elastic impedance between the more prominent features on $\mathrm{BH} 1, \mathrm{BH} 3$, and $\mathrm{BH} 2$,

- and an undifferentiated basalt unit at the bottom of BH1.

Several acoustic inversion schemes including model-based, band-limited, colored, and sparse-spike approaches were tested. The band-limited inversion (Figure 5) proved to be the most reliable as verified by error analysis involving a "hidden borehole" technique. This hidden borehole technique omits one or more boreholes

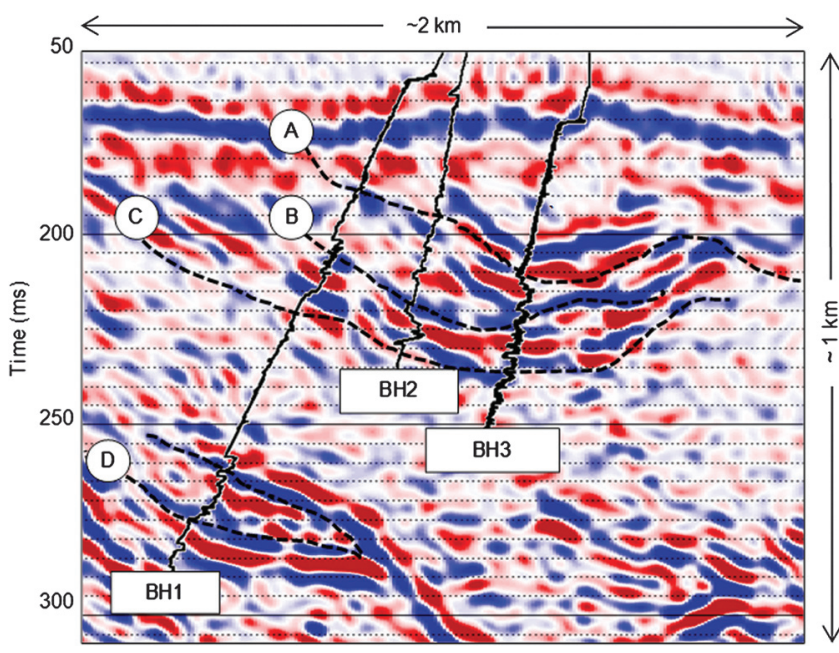

Figure 4. The rock contacts picked on the East Victory seismic line; enlarged section shown. Acoustic impedance logs are overlain for each borehole. (a) The Black Flag-banded iron formation near the Condenser dolerite. (b) A high gold content contact between an intermediate intrusion through the condenser dolerite (c) A dolterite/ intermediate intrusion into a shear zone with a low-amplitude reflection zone between the more prominent features on $\mathrm{BH} 1, \mathrm{BH} 2$, and BH3. (d) An undifferentiated basalt unit at the bottom of BH1.

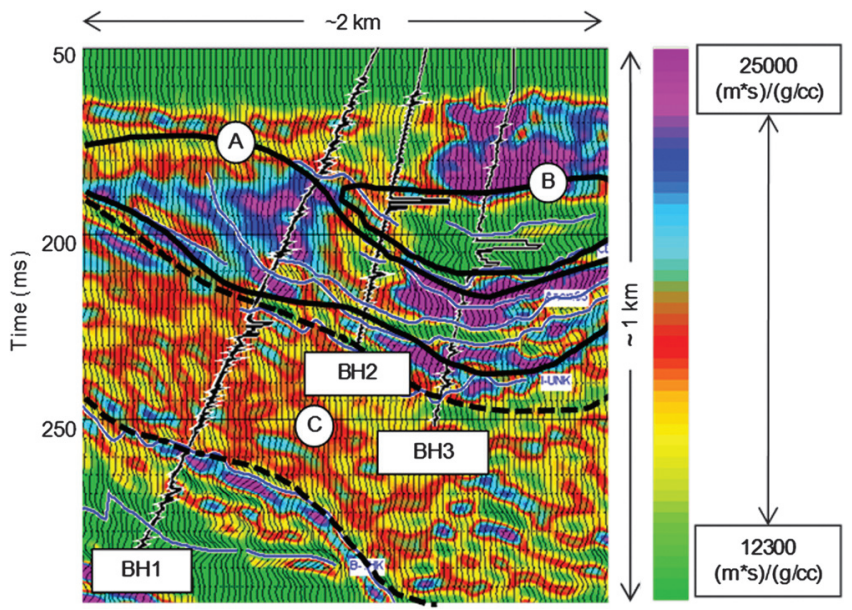

Figure 5. The band-limited inversion for the East Victory seismic line. Gold assays are shown for each borehole in Figure 6. "Harder rock" has an upper limit of $25000(\mathrm{~m} * \mathrm{~s}) *(\mathrm{~g} / \mathrm{cc})$ and "softer rock" has a lower limit of $12300(\mathrm{~m} * \mathrm{~s}) *(\mathrm{~g} / \mathrm{cc})$ impedance. (a) is the condenser dolerite, (b) is a high gold content intermediate intrusive, and (c) is the poorly reflecting shear zone. 
from the inversion process but not from the correlation process (Latimer and Van Riel, 2000). The inverted impedance at that borehole is then evaluated against the log-derived equivalent. If the two differ by a small amount (and the differences are random), the inversion process is considered to be reliable.

The results of the band-limited inversion in Figure 5 showed outlined nicely the location of an intermediate and volcaniclastic (b) package on top of the condenser dolerite (a) which coincides with high gold content (see also Figure 6). The extent of the shear zone (c) also is evident in Figure 5. Improved rock characterization may be achieved by including more seismic attributes in the inversion (Harrison and Urosevic, 2009). While these results are encouraging, further analysis and verification by drilling is required.

\section{AMPLITUDE VERSUS OFFSET}

AVO analysis has been used extensively in hydrocarbon exploration for pore fluid discrimination but offers a new application for hard-rock mineral exploration environments. "Fluid-analogous" hard-rock responses require investigation to assess whether these AVO effects may be related to lithology changes, rock alterations, or mineralized zones. Such effects, if any, would be, to a great degree, site-specific and would need to be reassessed on a case-bycase basis. We expect that AVO "anomalies" are dominated by Poisson's ratio change resulting from mineral composition differences but also are influenced by variations in the internal structure of the same rock due to fracturing and alterations. For this reason, a library

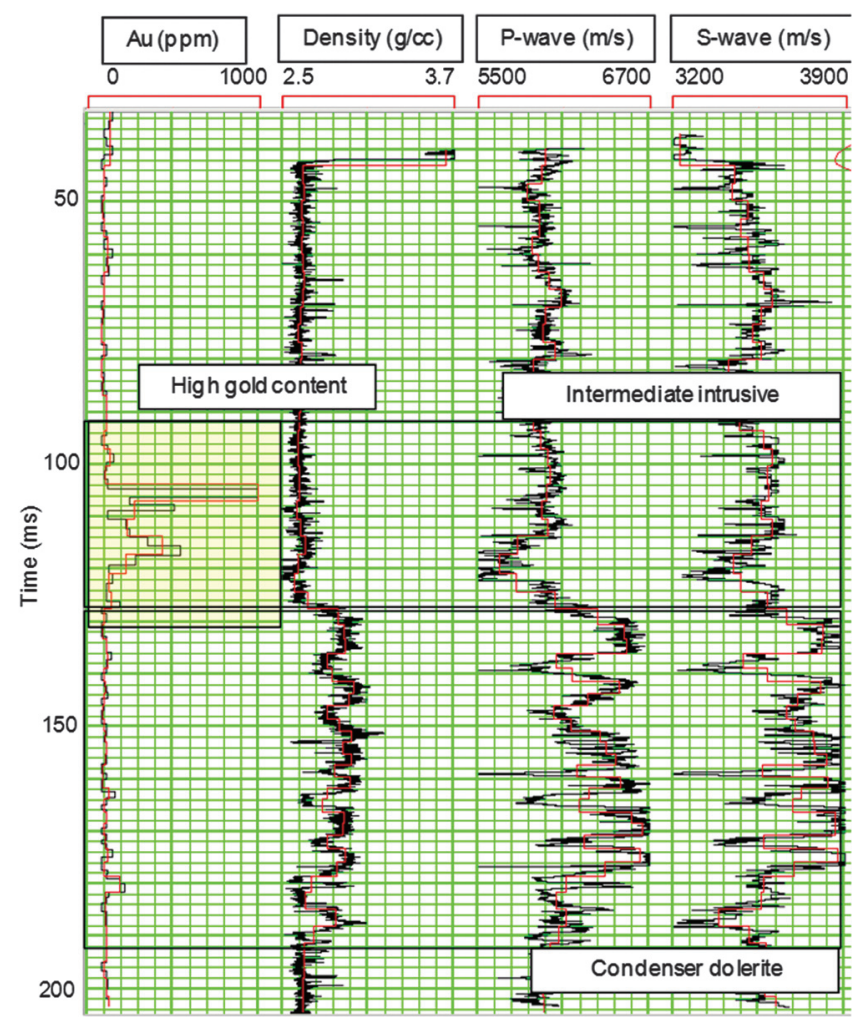

Figure 6. Gold content (left) in parts per million (ppm) with respect to density $(\mathrm{g} / \mathrm{cc}), \mathrm{P}$-wave $(\mathrm{m} / \mathrm{s})$, and S-wave $(\mathrm{m} / \mathrm{s})$ along borehole $\mathrm{BH} 3$. of AVO responses was generated using East Victory borehole data to understand resulting AVO effects. In Figure 6, the gold content is shown together with the density, P-wave, and S-wave logs for borehole BH3. To model the AVO response, we extracted a statistical wavelet from the seismic data (zero-phase, with power spectra averaged from 25 seismic traces around the well) and computed a synthetic gather using ray tracing and Zoeppritz equations (Figure 7). An increase of reflectivity with offset was observed. This could be attributed to a change of Poisson's ratio within the shear zone with respect to the host rock. Apart from the AVO effect, it is important to observe that the elastic contrast between high gold content intermediate intrusive and the denser Condenser dolerite is significant and is expected to produce strong reflection (red composite trace in Figure 7). The observed amplitude changes with offset were characterized and cataloged for each borehole. AVO modeling suggests that long offset reflection data may be beneficial for rock type analysis in this hard-rock environment.

Subsequent to this analysis, we constructed far-offset and nearoffset stacks. These partial offset stacks (0-600 and 600-1200 m, respectively) were subtracted from the full-offset stacks (Figure 8). The top panel highlights different lithologies, which are dominated by small angle reflectivity. The difference between far-offset versus full-offset stacks (bottom Figure 8) illustrates that large offsets are important for imaging in hard-rock environments. Known gold-bearing structures showed significant anomalies in the second panel as expected from the results of Figure 8 (increasing AVO gradient). However, the relationship is not simple due to structural

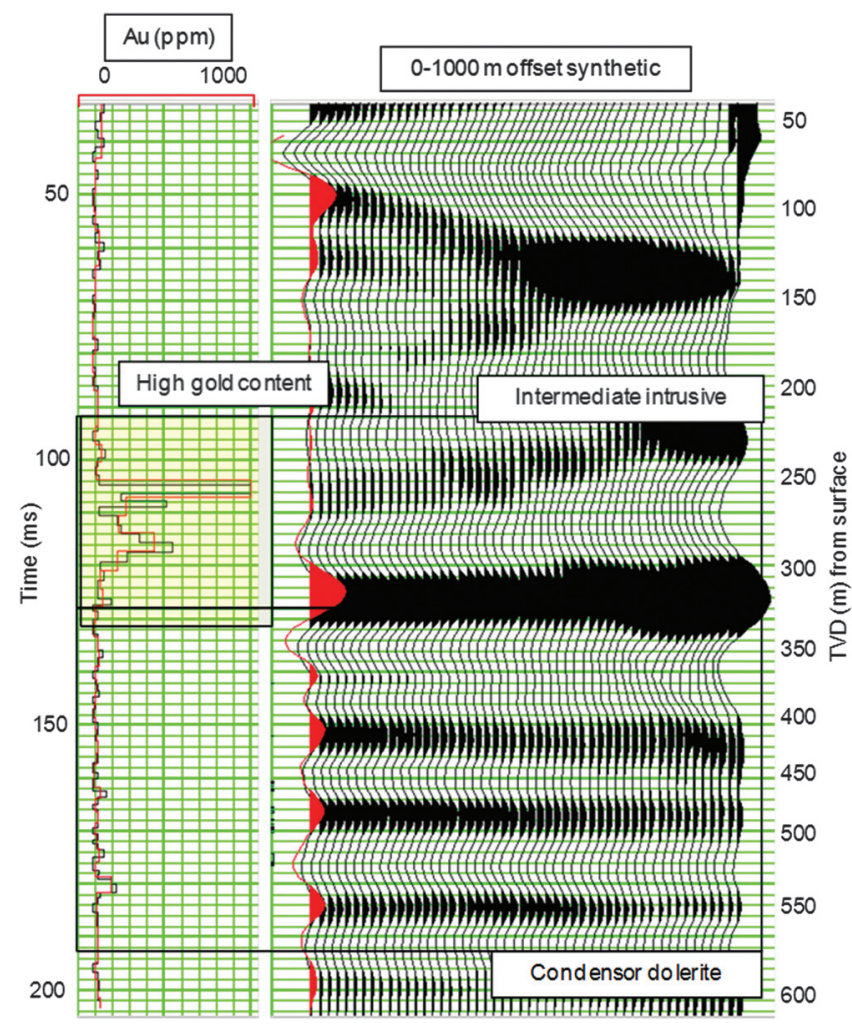

Figure 7. Gold content (left) and Zoeppritz synthetic (right) for borehole $\mathrm{BH} 3$. Overall reflectivity is given by the composite trace shown in red. 


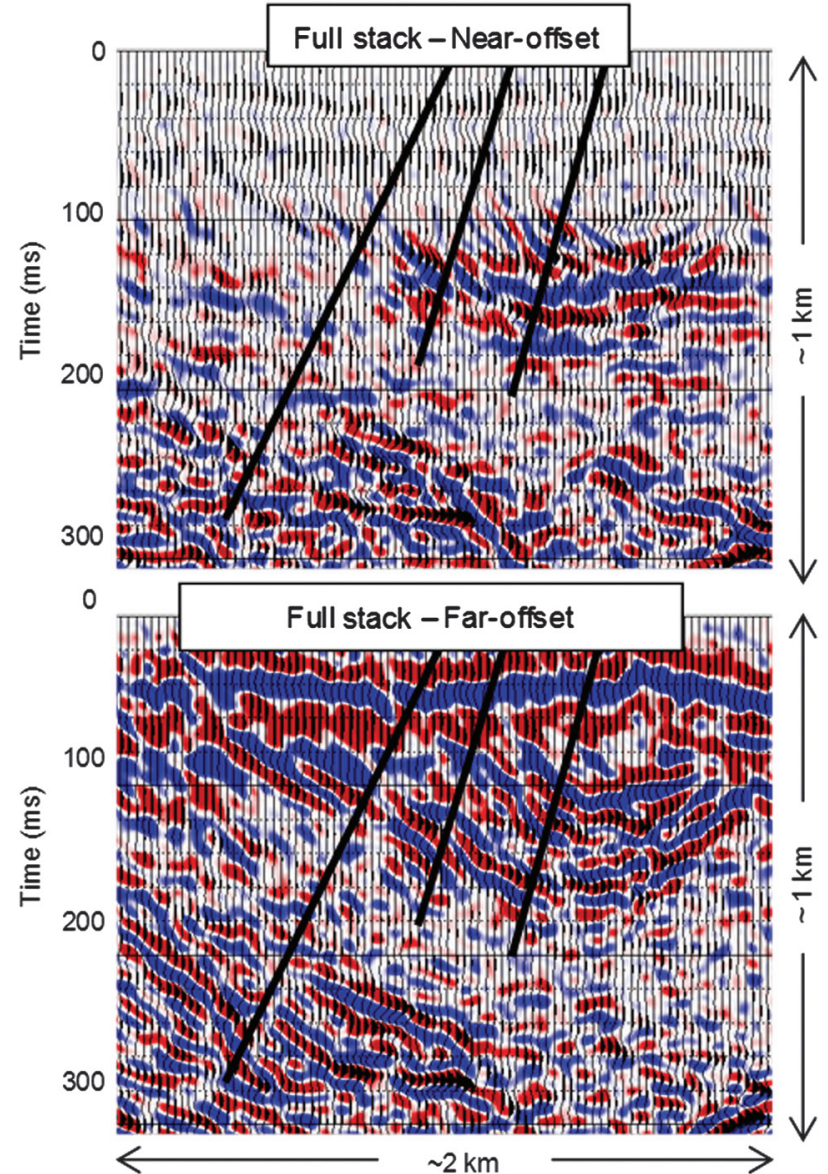

Figure 8. Differences between full-stack and near-offset (top), and full-stack and far-offset (middle). Known gold mineralizations (location of three boreholes) appear in the second panel due to associated anomalous AVO gradient.

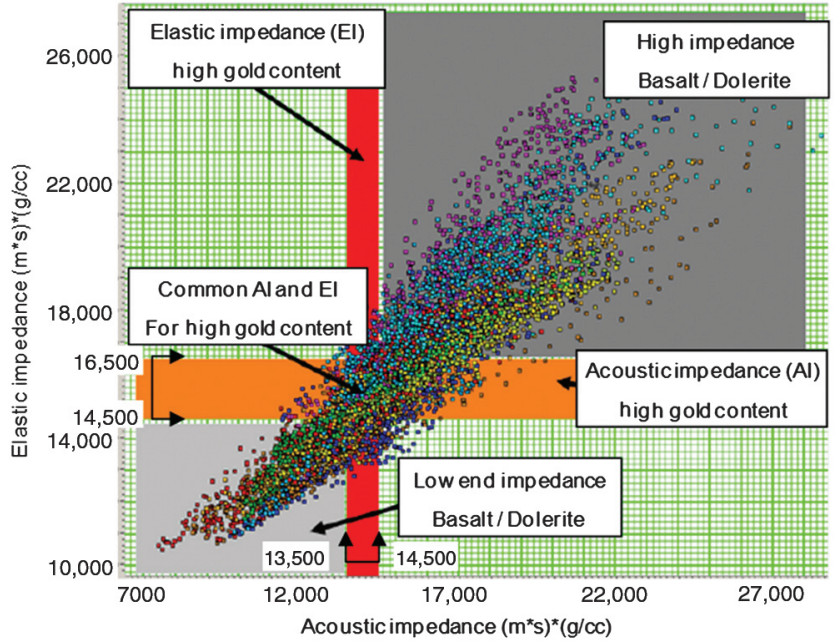

Figure 9. Crossplotting and zoning of elastic versus acoustic impedance values for near-offset band-limited inversions. complexities such as the presence of steeper reflections, which may obscure amplitude changes in mineralized zones.

\section{ELASTIC INVERSION}

Up until now, we have relied primarily on acoustic impedance from borehole logs. AVO analysis, however, suggests that variations in Poisson's ratio and possibly shear velocity could provide additional information in regards to the characterization of hard rocks. Hence, further analysis was carried through elastic inversion as suggested by Connolly (1999).
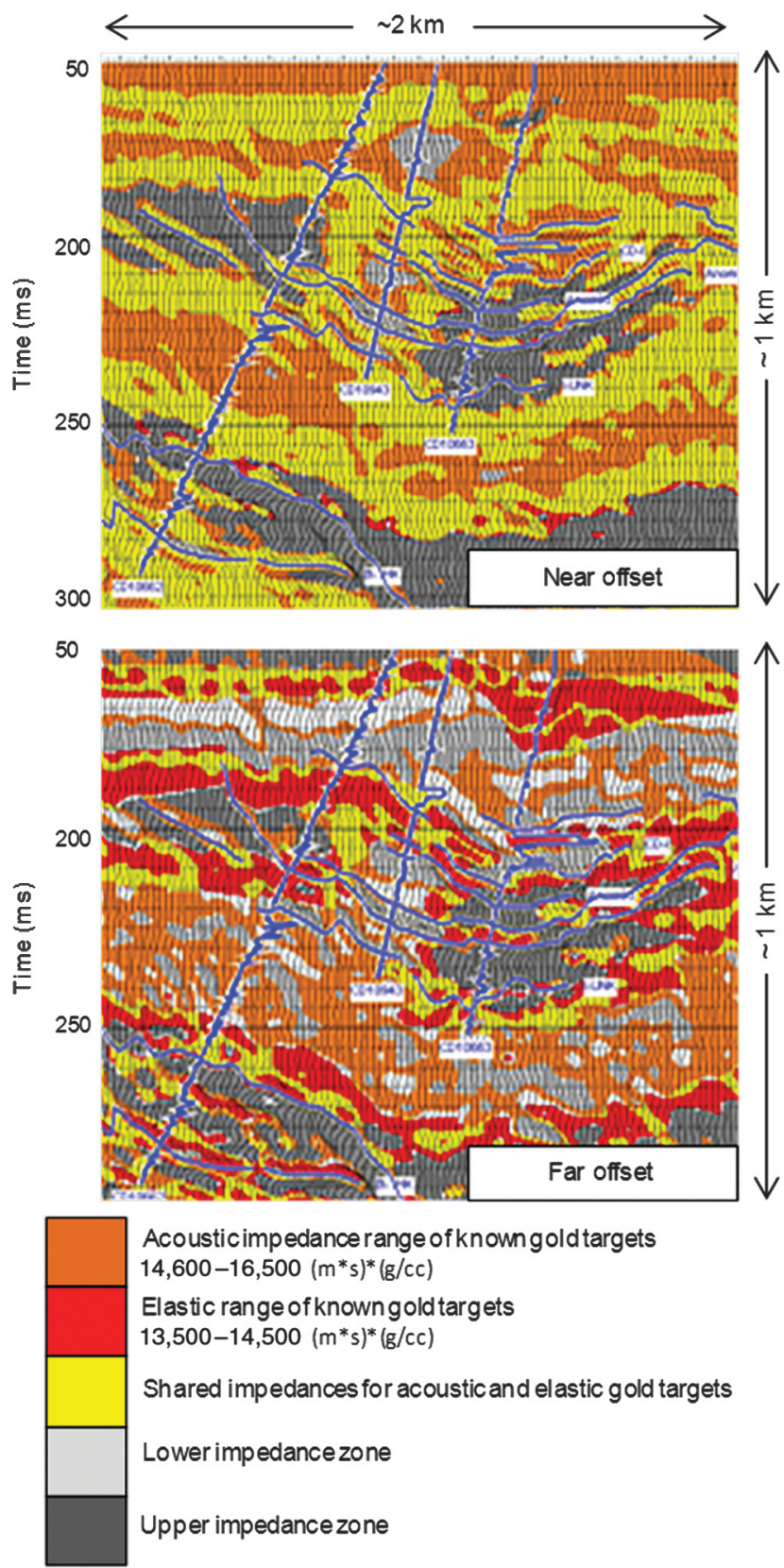

Figure 10. Crossplot and zoning results from Figure 9 applied to the near offset (top) and far offset (bottom). 
Well-ties were carried out on near-offset and far-offset partial stacks in a similar manner as for acoustic impedance inversion. Crossplots were then generated between acoustic impedance (AI) and elastic impedance (EI) for near-offset and far-offset stacks to observe possible relationships between $\mathrm{AI}$ and $\mathrm{EI}$ in this hard-rock environment. Zoning is then performed to separate different ranges within the data. Of particular interest was the relationship between AI high gold content and EI high gold content (Figure 9). Their intersecting region is constructed by using a narrow AI and EI range. Upper and lower acoustic and elastic impedance limits also are included for nongold, barring basalt, and dolerite. The same zones are plotted on the near-offset and far-offset stacks in Figure 10.

The AI-high gold content range is colored orange, while EI-high gold content range is colored red. The cross-over zone between acoustic and elastic impedance for the known potential gold occurrences is shown in yellow (Figure 10). These gold-bearing "predictions" appear to be related to characteristics of "softer" and "harder" rocks and should not be taken as a direct indication of gold content. This prediction is yet another parameter that, combined with other attributes and structural interpretation, may assist in targeting gold mineralization. The correlation is very good for far-offset section, which further emphasizes the importance of far offset in hard-rock exploration.

\section{CONCLUSIONS}

The application of seismic methods in hard-rock environments is fraught with many difficulties such as steeply dipping reflectors and/or subvertical intrusive, low $\mathrm{S} / \mathrm{N}$ resulting from high ambient noise and poor reflectivity, regolith heterogeneity, and access restrictions. While these difficulties are daunting, most of these issues can be addressed by optimizing survey geometry and acquisition parameters, choosing appropriate processing strategies, and performing data calibration using all available information such as FWS, core samples, and existing geologic models. By using the power of seismic attributes, AVO analysis and inversion, herein described, in a favorable geologic situation, it appears that it is possible to suggest the zones where gold mineralization is likely to occur.

Our analysis showed that fine detail, in complex shallow structure and deep structure, was revealed in seismic images for the East Victory line. Surface mapping and drilling confirmed the interpreted location and dip of the Boulder-Lefroy fault, Repulse fault, and the Foster thrust. Black Flag-banded iron formation, condenser dolerite intermediate intrusion, and other smaller structures of relevance to gold mineralization were successfully identified.

Numerical modeling showed that gold zones at the St. Ives site are likely to be associated with elevated reflectivity and AVO effects. Subsequent partial stacks and their differences highlighted the extent of "hard" and "soft" rocks.

Acoustic impedance was not a strong indicator of mineralized zones but may prove useful when combined with elastic impedance. Near-offset stacked images and inversions revealed more detailed predictions at shallower target zones, which would be of economic interest for mineral exploration. The inversion study we performed showed a potential for this method in predicting the extent of possible gold mineralization The results of inversion, however, remain difficult to assess, particularly for 2D seismic data. Further borehole information is required to more accurately evaluate the potential of the approach taken in this study.

We note finally that improved correlation through the availability of better and more frequent logging, core studies, and the application of VSP should enable more accurate AVO studies and further advances along the path of relating the rock types to the elastic properties inverted from seismic data.

While 2D inversion and AVO showed promise, the future more frequent application of high-resolution 3D seismic will enable better illumination and imaging of complex structures as well as recovery of true relative amplitudes, and thus will potentially allow more rigorous use of seismic attributes such as AI, EI, and reconnaissance AVO attributes for hard-rock characterization and targeting of deep mineral reserves.

\section{ACKNOWLEDGMENTS}

Support for this study provided by Gold Fields and Curtin University Department of Exploration Geophysics is highly appreciated. We also acknowledge Halliburton (Landmark Graphics) and Fugro (Hampson \& Russell Software Services), who provided software necessary for this study.

\section{REFERENCES}

Cassidy, K. F., and S. G. Hagemann, 2001, 'World class' Achaean orogenic gold deposits eastern Yilgarn Craton: Diversity in timing, structural controls and mineralization styles: Geoscience Australia, 17, 382-384.

Connolly, P., 1999, Elastic impedance: The Leading Edge, 18, 438-452, doi: $10.1190 / 1.1438307$

Cox, M. J. G., 1999, Static corrections for seismic reflection surveys: SEG. Cox, S. F., and K. Ruming, 2004, The St Ives mesothermal gold system, western Australia - A case of golden aftershock: Journal of Structural Geology, 26, 1109-1125, doi: 10.1016/j.jsg.2003.11.025.

Denham, D., 2008, Where to look for gold: Preview (Magazine of the Australian Society of Exploration Geophysicists), 135, 22-24.

Drummond, B. J., B. R. Goleby, A. J. Own, A. N. Yeates, C. Swager, Y. Zhang, and J. K. Jackson, 2000, Seismic reflection imaging of mineral systems: Three case histories: Geophysics, 65, 1852-1861, doi: 10 $.1190 / 1.1444869$.

Goleby, B. R., B. J. Drummond, A. J. Owen, A. N. Yeates, J. Jackson, C. Swager, and P. Upton, 1997, Structurally controlled mineralisation in Australia - How seismic profiling helps find minerals: Recent case histories, in A. G. Gubins, ed., Proceedings of Exploration '97: 4th Decennial International Conference on Mineral Exploration, 409-420.

Hampson, D., and M. Galbraith, 1981, Wavelet extraction by sonic log correlation: Canadian Journal of Exploration Geophysicists, 17, no. 1, 24-42.

Harrison, C., and M. Urosevic, 2009, Towards direct detection of gold bearing rock formations from seismic data, St. Ives gold camp, western Australia: Presented at the 20th International Geophysical Conference and Exhibition, ASEG.

Hatherly, P. J., M. Urosevic, A. Lambourne, and B. J. Evans, 1994, A simple approach to calculating refraction statics corrections: Geophysics, 59 , 156-160, doi: 10.1190/1.1443527.

Juhlin, C., 1990, Interpretation of the reflections in the Siljan Ring area based on results from the Gravberg-1 borehole: Tectonophysics, 173, 345-360, doi: 10.1016/0040-1951(90)90229-2.

Latimer, R. B., and P. Van Reil, 2000, An interpreter's guide to understanding and working with seismic-derived acoustic impedance data: The Leading Edge, 19, 242-249.

Milkereit, B., and D. W. Eaton, 1996, Towards 3D seismic exploration technology for the crystalline crust, in S. E. Lawton, ed., Trends, technologies, and case histories for the modern explorationist: Prospectors and Developers, Association of Canada, Short Course notes, 17-36.

Perron, G., and A. J. Calvert, 1998, Shallow, high resolution seismic imaging at the Ansil mining camp in the Abitibi greenstone belt: Geophysics, 63, 379-391, doi: 10.1190/1.1444337.

Stolz, E., M. Urosevic, and K. Connors, 2004, Reflection seismic surveys at St. Ives gold mine, WA: Presented at the 17th Geophysical Conference and Exhibition, ASEG.

Urosevic, M., and C. Juhlin, 2007, An analysis of seismic information obtained from crooked line seismic surveys in crystalline rocks, Australia: Presented at the 69th Annual International Conference and Exhibition, EAGE. 
Urosevic, M. A. Kepic, E. Stolz, and C. Juhlin, 2007, Seismic exploration of ore deposits in western Australia: Advances in regional exploration, in Proceedings of Exploration 07: Fifth Decennial Conference on Mineral Exploration, DMEC, 525-534.

Urosevic, M., E. Stoltz, and S. Massey, 2005, Seismic exploration for gold in a hard rock environment - Yilgarn Craton, western Australia: Presented at the 67th Annual International conference and Exhibition, EAGE.
Vearncombe, J. R., 1998, Shear zones, fault networks, and Archean gold: Geology, 26, 855-858, doi: 10.1130/0091-7613(1998)026<0855: SZFNAA $>2.3 . \mathrm{CO} ; 2$.

Weinberg, R. F., P. Van der Borgh, R. J. Bateman, and D. I. Groves, 2005 , Kinematic history of the Boulder-Lefroy shear zone system and controls on associated gold mineralization, Yilgarn Craton, western Australia: Economic Geology, 100, 1407-1426. 